\title{
CARACTERIZAÇÃO MORFOLÓGICA E QUÍMICA DE MIMOSA CAESALPINIIFOLIA SUBMETIDA À ADUBAÇÃO COM P*
}

\author{
MORPHOLOGICAL AND CHEMICAL CHARACTERIZATION OF MIMOSA \\ CAESALPINIIFOLIA SUBMITTED TO PHOSPHORUS FERTILIZATION \\ Caldas, G.G. ${ }^{1}$, Dos Santos, M.V.F. ${ }^{2 A}$, Lira Junior, M.A. ${ }^{2 B}$, Ferreira, R.L.C. ${ }^{2 C}$, \\ Da Cunha, M.V. ${ }^{2 \mathrm{D}}$, Lira, M. de A. ${ }^{3}$, Bezerra Neto, E. ${ }^{2 \mathrm{E}}$ e Galdino, A.C. ${ }^{4}$
}

\begin{abstract}
${ }^{1}$ Escola Agrotécnica Federal de Barreiros. PE. Fazenda Sapé. CP 021. Barreiros-PE. CEP 55560-000. Brasil. glauco.caldas@hotmail.com

2Universidade Federal Rural de Pernambuco (UFRPE). Av. Manoel de Medeiros, s/n. Dois Irmãos. RecifePE. CEP 52171-900. Brasil. Amercia@dz.ufrpe.br; ${ }^{B}$ mario.lira@depa.ufrpe.br; Crinaldo@dcfl.ufrpe.br; Dmarciovc@msn.com; Eegidio@dq.ufrpe.br

${ }^{3}$ Instituto Agronômico de Pernambuco. Av. Gal San Martin, 1371. Caixa Postal 1022. Bonji. Recife-PE. CEP 50761-000. Brasil. mariolira@terra.com.br

4Programa de Pós-Graduação em Zootecnia da UFRPE. adicg@pop.com.br
\end{abstract}

\section{PalaVRas ChaVE ADICIONAIS}

Acúleo. Altura. Leguminosa. Tanino. Sazonalidade.

\section{RESUMO}

Foram avaliados os componentes morfológicas e composição química de plantas de Mimosa caesalpiniifolia Benth submetidas a adubação fosfatada e em diferentes épocas do ano. O experimento foi conduzido na Estação Experimental de Itambé do Instituto Agronômico de Pernambuco. Foi utilizado delineamento em blocos ao acaso em parcelas subdivididas, sendo os níveis de fósforo $\left(0,100\right.$ e $200 \mathrm{~kg}$ de $\mathrm{P}_{2} \mathrm{O}_{5} / \mathrm{ha}$ ) como parcelas e época de avaliação (seca e chuvosa) como subparcelas. A área experimental foi um bosque de sabiá com aproximadamente 13 anos e área de 0,3 ha com espaçamento 3,0 x 3,0 m, constituído de 210 plantas. Cada parcela experimental foi representada por uma planta circundada por oito plantas competitivas, que não receberam os tratamentos. As avaliações morfológicas foram realizadas em seis períodos com intervalos de 60 dias, quando foram realizadas coletas de folhas e ramos com diâmetro de até $5 \mathrm{~mm}$. Observou-se efeito da adubação fosfatada apenas para comprimento dos ramos, sendo de 202,1; 193,6 e $173,5 \mathrm{~cm}$ para 0,100 e $200 \mathrm{~kg} \mathrm{P}_{2} \mathrm{O}_{5} / \mathrm{ha}$, respecti-

*Parte da dissertação do primeiro autor, financiado pelo CNPq.

Recibido: 17-11-08. Aceptado: 4-2-09.

\section{ADDITIONAL KEYWORDS}

Thorn. Height. Legume. Tannin. Seasonality.

vamente. Para as demais variáveis, observou-se efeito somente do período de avaliação, tendo valores médios de $195,3 \mathrm{~cm} ; 24,6 ; 8,8 \mathrm{~mm}$ e 3,8 para altura, número de brotações, espessura de ramos e número de acúleos, respectivamente. Observou-se interação entre período de avaliação e adubação fosfatada apenas para a FDN dos ramos e efeito tanto do período quanto da adubação fosfatada sobre o teor de tanino nos ramos. A adubação fosfatada não influenciou a maioria dos componentes morfológicas e a composição química das plantas de sabiá.

\section{SUMMARY}

Morphological components and chemical composition of Mimosa caesalpiniifolia Benth plants submitted to phosphorus fertilization and at different season were evaluated. The experiment was conducted at the Itambé Experimental Station of Pernambuco Agronomical Institute. Statistical analysis assumed a randomized block design, with split-plot treatment design composed by phosphorus levels $\left(0,100\right.$ and $200 \mathrm{~kg}$ of $\mathrm{P}_{2} \mathrm{O}_{5}$ per hectare) as main plots and evaluation season (dry and rainy) as split-plots. Experimental area was a

Arch. Zootec. 59 (228): 529-538. 2010. 
sabiá woodlot, approximately 13 years old, measuring 0.3 ha with plant spacing of $3.0 \times 3.0$ $\mathrm{m}$ and 210 plants. Each experimental plot comprised one plant surrounded by eight competitive plants, not submitted to the treatments. Morphological evaluations were conducted at six periods, with 60 days interval, when leaves and branches up to $5 \mathrm{~mm}$ diameter were collected. Phosphorus effect was observed only for branch length, being 202.1 193.6 and $173.5 \mathrm{~cm}$ for 0,100 and $200 \mathrm{~kg} \mathrm{P}_{2} \mathrm{O}_{5} / \mathrm{ha}$, respectively. For the remaining variables, effects were only observed for evaluation period, with average values of $195.3 \mathrm{~cm}, 24.6,8.8 \mathrm{~mm}$ and 3.8 for plant height, branch number and diameter, and thorn number, respectively. Interaction between evaluation period and phosphorus fertilization was observed only for NDF of branches, and both period and phosphorus fertilization on tannin content of branches.

\section{INTRODUÇÃO}

O Nordeste brasileiro apresenta irregularidade na distribuição de chuvas, com períodos de estiagem extensos, que induzem a baixa produtividade dos rebanhos manejados sob pastejo. Entre as diversas espécies nativas de interesse forrageiro, merece destaque a leguminosa sabiá (Mimosa caesalpiniifolia Benth.) que, segundo Drumond et al. (2004), destaca-se pelo seu potencial madeireiro, bem como por apresentar resistência a seca. A planta apresenta grande diversidade morfológica, existindo exemplares com muito pouco ou sem acúleos (Lima et al., 2008), sendo bastante selecionada pelos animais em pastejo (Vieira et al., 2005).

O valor nutritivo de uma planta forrageira depende da composição química e de sua digestibilidade (Pereira Filho et al., 2007; Carvalho e Pires, 2008), que pode variar com a espécie, idade da planta, época do ano, entre outros fatores (Van Soest, 1994).

A introdução de leguminosa na pastagem tem proporcionado aumentos na quantidade de $\mathrm{N}$ ao sistema, favorecendo o ganho de peso animal e diversificando a dieta do animal (Carvalho e Pires, 2008).

Por outro lado, o fósforo é essencial para o desenvolvimento radicular e rebrota, sua deficiência diminui o valor nutritivo da forragem, dificultando o estabelecimento e desenvolvimento das plantas forrageiras e limitando a capacidade produtiva das pastagens (Moreira et al., 2002). Segundo Oliveira et al.(2002), para que seja possível atingir sustentabilidade a longo prazo em solos com baixa disponibilidade natural de fósforo, característicos da maioria dos solos brasileiros, a adição deste elemento, através do uso de fertilizantes torna-se imprescindível.

Assim, objetivou-se avaliar as características morfológicas e a composição química de plantas de Mimosa caesalpiniifolia Benth., submetidas à doses de adubação fosfatada, ao longo do ano.

\section{MATERIALE MÉTODOS}

O experimento foi conduzido na Estação Experimental de Itambé-PE, pertencente ao Instituto Agronômico de Pernambuco (IPA). O município de Itambé localiza-se nas coordenadas geográficas $07^{\circ} 25 \mathrm{~S}$ e $35^{\circ} 06 \mathrm{~W}$, na microrregião fisiográfica da Mata Seca de Pernambuco, a $190 \mathrm{~m}$ de altitude. Esta estação tem registrado precipitação anual média de $1200 \mathrm{~mm}$ e temperatura anual média de $25^{\circ} \mathrm{C}(\mathrm{CPRH}, 2003)$. A vegetação é classificada como Floresta Caducifólia e Subcaducifólia (IPA, 1994) e o solo é classificado como Argiloso VermelhoAmarelo, de acordo com o Sistema Brasileiro de Classificação de Solos (EMBRAPA, 1999). O índice pluviométrico durante o período experimental está representado na figura 1.

Foi utilizado um bosque de sabiá (Mimosa caesalpiniifolia Benth.), com aproximadamente 13 anos e área de 0,3 ha com espaçamento $3,0 \times 3,0 \mathrm{~m}$, constituído de 210 plantas. A parcela experimental foi representada por uma planta circundada por oito plantas competitivas, não experimentais que não receberam qualquer tratamento.

O bosque estudado é oriundo de proge- 
nitores F4, obtidas de plantas sem acúleo, a partir de matrizes do bosque da Universidade Federal Rural de Pernambuco, e de um plantio comercial normal do Campo Experimental de Itambé-PE (Lima et al., 2008). A vegetação anterior ao plantio de sabiá era constituída de braquiária (Brachiaria decumbens Stapf.), permanecendo esta espécie nas margens do bosque, representando aproximadamente $20 \%$ da área total (Vieira et al., 2005).

Foi retirada uma amostra composta de solo da área para a realização da análise química à profundidades de 0-20 e 20-40 $\mathrm{cm}$, antes da aplicação dos tratamentos segundo as metodologias descritas em EMBRAPA (1997). O resultado da análise do solo para as profundidades de $0-20$ e 20 $40 \mathrm{~cm}$, respectivamente, foi: $\mathrm{pH}$ (água 1:2,5) 4,90 e 4,$97 ; \mathrm{P}\left(\mathrm{mg} / \mathrm{dm}^{3}\right) 7$ e $6 ; \mathrm{K}+0,51$ e 0,25 ; $\mathrm{Ca}^{2+}+\mathrm{Mg}^{2+} 4,10$ e 3,$75 ; \mathrm{Ca}^{2+} 2,7$ e 2,5 e $\mathrm{Al}^{3+}$ $\left(\mathrm{cmolc} / \mathrm{dm}^{3}\right)$ 0,6 a 0,5.

O corte de uniformização das plantas, a uma altura de $50 \mathrm{~cm}$ do solo, foi realizado em maio e junho de 2004, sendo o critério para a formação dos blocos I e II, respectivamente.

Três níveis de fósforo (equivalentes a 0 , 100 e $200 \mathrm{~kg} \mathrm{de} \mathrm{P}_{2} \mathrm{O}_{5} / \mathrm{ha}$ ) foram aplicados em maio e junho de 2004 nos blocos II e I respectivamente, na forma de superfosfato simples. A adubação foi realizada a lanço, logo após o corte de uniformização, na forma de meia circunferência sobre a superfície do solo próximo ao tronco da parcela experimental.

As avaliações morfológicas foram realizadas em julho, setembro e novembro de 2004 e janeiro, março e maio de 2005. A época chuvosa compreendeu aos meses de julho 2004, março e maio de 2005 , enquanto que a época seca correspondeu aos meses de setembro e novembro de 2004 e janeiro 2005.

Foram avaliadas: altura de planta, forragem pastejável, número de brotações, comprimento e espessura dos ramos, número de acúleos $/ 10 \mathrm{~cm}$ linear e tipos de fuste.

Para altura de planta utilizou-se régua graduada posicionada junto ao tronco principal até o ápice da planta. Para número de

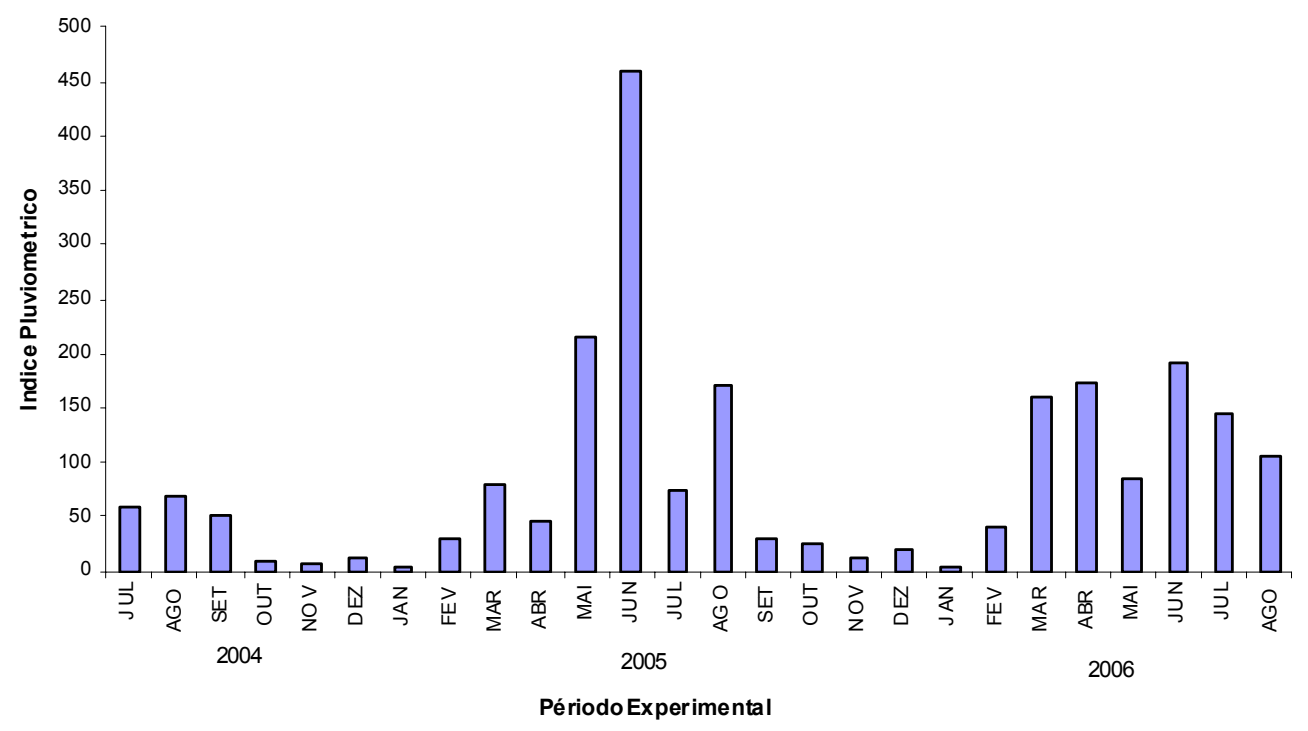

Figura 1. Precipitação de julho de 2004 a agosto de 2006, Itambé-PE. (July 2004 to August 2006 precipitation, Itambé-PE). 
brotações, foram consideradas todas as ramificações visíveis. Para a medição da espessura dos ramos, utilizou-se paquímetro com mensuração na porção mediana. Para comprimento dos ramos foi utilizada uma régua graduada posicionada sobre os ramos a partir do ponto de rebrotação. $\mathrm{O}$ número de acúleos foi contado em três ramos de cada planta, numa extensão de $10 \mathrm{~cm}$ de comprimento da região média do ramo. Para avaliação do tipo de fuste, considerouse a inclinação do fuste com relação ao ponto de rebrotação, sendo classificadas como retilíneo, semi-retilíneo e curvilíneo e atribuídas as notas 1,2 e 3, respectivamente.

A forragem pastejável compreendeu ramos com até $5 \mathrm{~mm}$ de diâmetro e folhas a 2 $m$ de altura em relação ao solo, colhida com auxilio de uma tesoura a cada 60 dias. Após a colheita, a forragem pastejável foi pesada e separada em folhas e ramos para determinação da proporção destes na amostra. Em seguida, amostras foram levadas à estufa para determinação da matéria seca a $55^{\circ} \mathrm{C}$ por aproximadamente 48 horas. A forragem pastejável foi expressa em $\mathrm{kg}$ de $\mathrm{MS} / \mathrm{ha}$, baseada na área média ocupada por cada planta em função do espaçamento inicial.

As coletas de forragem pastejável e para análises químicas referentes a época seca foram realizadas em setembro e novembro de 2005 e fevereiro de 2006, as coletas da época chuvosa nos meses de abril, junho e agosto de 2006.

Amostras de forragem pastejável foram utilizadas para determinação dos teores de matéria seca (MS), proteína bruta (PB), material mineral (MM) e fósforo $(\mathrm{P})$, conforme metodologia descrita por Silva e Queiroz (2002) e fibra em detergente neutro (FDN), fibra em detergente ácido (FDA), conforme metodologia de Van Soest (1967). As análises foram realizadas no Laboratório de Nutrição Animal da Universidade Federal Rural de Pernambuco - UFRPE. A determinação de tanino foi realizada no Laboratório de Química Vegetal da UFRPE, segundo metodologia de Folin-Denis (AOAC, 1995).
Para análise estatística foi considerado um delineamento em blocos ao acaso em parcelas subdivididas. Os fatores estudados foram níveis de fósforo $(0,100$ e $200 \mathrm{~kg}$ de $\mathrm{P}_{2} \mathrm{O}_{5} /$ ha) como parcelas e épocas de avaliação (seca e chuvosa) como subparcelas. Os blocos I e II foram repetidos seis e sete vezes, respectivamente, visando maior precisão do experimento, conforme PimentelGomes (2000). Os dados foram analisados usando o SAS, versão 8.0 (SAS, 1999). As médias das variáveis analisadas foram comparadas por meio do teste $\mathrm{F}$ e teste de Tukey dependendo do número de tratamentos da comparação, a 5\% de probabilidade.

\section{RESULTADOSEDISCUSSÃO}

Não se observou efeito significativo do fósforo $(p>0,05)$ para a altura, espessura dos ramos, número de brotações, número de acúleos e forragem pastejável de plantas de sabiá. No entanto, efeitos do período do ano $(p<0,05)$ foram observados para altura, comprimento e espessura dos ramos. Para nenhuma dessas variáveis foi observada efeito significativo $(p>0,05)$ para a interação entre fósforo e época de avaliação.

A ausência de efeito de fósforo na altura de plantas de sabiá também foi encontrada por Burity et al. (2000). É possível que esta ausência de efeito, apesar da baixa disponibilidade de fósforo do solo, seja efeito da aplicação localizada do adubo. Esta localização pode ter induzido a competição pelo nutriente, pois, as plantas vizinhas não receberam adubação, e podem ter sido fortes competidoras, o que diminuiria a oferta do mesmo para a parcela experimental. Vale ressaltar que, as brotações eram relativamente novas, com um ano. Ao mesmo tempo, como as plantas provavelmente apresentavam sistema radicular bastante desenvolvido, por não serem plantas novas, é possível que a redistribuição interna de fósforo tenha contribuído para o reduzido efeito da fertilização.

Observou-se efeito de período do ano 
para altura, comprimento e espessura dos ramos, tendo as plantas apresentado maior desenvolvimento no período seco (tabela I). Este comportamento pode ser justificado pela época de realização do corte de uniformização, no meio do período chuvoso, portanto, a planta intensificou o seu crescimento na época seca, tendo redução no seu desenvolvimento na época chuvosa, do ano de 2005, com a maior idade das plantas. Deve ser considerado também que a maior altura da planta, comprimento e espessura dos ramos na época seca é resultante da soma do crescimento das duas épocas, já que as medições foram cumulativas.

O tratamento sem adubação fosfatada apresentou 202,1 cm de comprimento de ramos em média e foi superior aos demais. $\mathrm{O}$ tratamento com $100 \mathrm{~kg}$ de $\mathrm{P}_{2} \mathrm{O}_{5} /$ ha foi superior ao de $200 \mathrm{~kg}$ de $\mathrm{P}_{2} \mathrm{O}_{5} /$ ha com médias de 193,6 e $173,5 \mathrm{~cm}$, respectivamente. O efeito positivo da adubação fosfatada no comprimento dos ramos era esperado, mas não se confirmou. Entretanto, isso pode estar relacionado à forma de distribuição do adubo e a pouca mobilização do nutriente no solo. Além disto, considerando os resultados para número de brotações, supõem-se que o $\mathrm{P}$ pode ter estimulado o número de brotações, reduzindo o desenvolvimento individual de ramos.
O número de acúleos não variou com o período de avaliação, conforme poderia ser esperado em função do forte caráter hereditário desta característica. Vale ressaltar a importância da mensuração dessa variável, considerando que a maior ocorrência de acúleos diminui a preferência da planta pelos animais, conforme observado por Vieira et al. (2005), além de dificultar a colheita de estacas. Segundo Lira et al. (1996), há uma correlação linear negativa significativa entre o caráter número de acúleos e preferência pelos bovinos, sendo as plantas mais consumidas à medida que apresentam menos acúleos.

O fuste das plantas não foi afetado pelo período ou pela adubação fosfatada $(p>0,05)$, sendo a média do tipo semi-retilíneo. Vale ressaltar que estacas de sabiá são bastante utilizadas por produtores para confecção de cercas, conforme observado por Almeida et al. (2006a), sendo a variação de preço de estacas de diferentes tipos determinada, em particular, pela retilinearidade das estacas, bem como pelo seu diâmetro.

A forragem pastejável não foi influenciada pelos níveis de fósforo, nem pelo período do ano. Apesar de ser uma espécie caducifólia, provavelmente o nível de umidade residual no solo do bosque durante o período seco foi suficiente para manter as folhas e ramos de até $5 \mathrm{~mm}$ na planta, além

Tabela I. Características de plantas de sabiá, conforme o período de avaliação. (Sabiá plant characteristics, according to evaluation period).

\begin{tabular}{|c|c|c|c|c|c|c|c|}
\hline Período & $\begin{array}{c}\text { Altura } \\
(\mathrm{cm})^{1}\end{array}$ & $\begin{array}{c}\mathrm{N}^{\circ} \\
\text { brotações }^{1}\end{array}$ & $\begin{array}{l}\text { Comprimento } \\
\text { dos ramos } \\
(\mathrm{cm})^{1}\end{array}$ & $\begin{array}{l}\text { Espessura } \\
\text { dos ramos } \\
\qquad(\mathrm{mm})^{1}\end{array}$ & $\begin{array}{l}\text { Acúleos } \\
\left(\mathrm{n}^{\circ} / \mathrm{cm}^{2}\right)^{1}\end{array}$ & $\begin{array}{l}\text { Tipo de } \\
\text { fuste }^{1}\end{array}$ & $\begin{array}{c}\text { Forragem } \\
\text { pastejável } \\
(\mathrm{kg} \mathrm{MS/ha/60dias})^{2}\end{array}$ \\
\hline Chuva & $165,36^{b}$ & $23,37^{a}$ & $156,46^{b}$ & $7,61^{b}$ & $2,99^{a}$ & $1,88^{a}$ & $158,16^{a}$ \\
\hline Seca & $205,72^{a}$ & $24,50^{a}$ & $199,66^{a}$ & $10,16^{a}$ & $3,32^{a}$ & $1,92^{a}$ & $146,94^{a}$ \\
\hline
\end{tabular}

${ }^{a b}$ Médias seguidas da mesma letra na coluna não diferem entre si pelo teste de $F(p>0,05)$.

1Época chuvosa julho 2004 e março e maio de 2005, época seca setembro novembro de 2004 e janeiro 2005.

Época chuvosa abril, junho, agosto 2006, e período seco setembro, novembro 2005 e fevereiro 2006. 
da precipitação do período experimental ter sido superior à média histórica da região. A proporção de folhas e de ramos na forragem pastejável foi de $59 \%$ e $41 \%$, respectivamente. Moura et al. (2006) observaram valor de $1,67 \%$ para folha e $98,33 \%$ para ramo, considerando entretanto, todo tipo de ramo presente na planta e não apenas ramos finos que representam o material a ser selecionado pelo animal, como no presente trabalho.

Considerando a média de forragem pastejável de 152,5 kg de MS/ha/60 dias, estima-se uma produção anual de $915,0 \mathrm{~kg}$ de MS de forragem pastejável, valor esse inferior aos observados na literatura para leguminosas. Entretanto, vale ressaltar que a maior produção de plantas de sabiá observada por Moura et al. (2006) equivale a toda a parte aérea da planta e não apenas a forragem pastejável, como na presente pesquisa.

Para a maioria das variáveis de composição química, foi observado efeito significativo $(\mathrm{p}<0,05)$ do período de avaliação, com exceção da MM de ramos, que não foi influenciada por qualquer efeito estudado. Observou-se interação significativa $(\mathrm{p}<0,05)$ apenas entre período de avaliação e adubação fosfatada para a FDN dos ramos e efeito significativo $(\mathrm{p}<0,05)$, tanto do período quanto da adubação fosfatada sobre o teor de tanino nos ramos.

Para matéria seca, observa-se que a sabiá apresentou diferença significativa $(\mathrm{p}<0,05)$ entre os períodos, tanto para folha como ramo, apresentando maior valor para época seca, o que já era esperado, considerando que se trata de uma espécie caducifólia (tabela II). Os valores encontrados estão bem próximos aos relatados por Vieira et al. (2005) e Almeida et al. (2006b), tanto para o período seco como o chuvoso.

Para proteína bruta observou-se diferença significativa $(\mathrm{p}<0,05)$ entre os períodos, tanto para folha quanto para o ramo, apresentando valores superiores para o período chuvoso, provavelmente devido ao fato de que a maior atividade fotossintética permitida pelo aumento na disponibilidade hídrica, incrementa a fixação biológica de nitrogênio. Os resultados observados para época chuvosa são próximos aos observados por Araújo Filho et al. (2002) e superiores aos encontrados por Guimarães-Beelen et al. (2006) para sabiá na fase vegetativa. Os valores médios observados de proteína bruta para as duas frações da planta em função dos períodos de avaliação, exceto ramos no período seco, foram superiores ao mínimo necessário para dieta de ruminantes, o que evidencia a importância da leguminosa estudada como suporte alimentar, notadamente nas áreas de baixa precipitação do Nordeste Brasileiro, considerando ser uma espécie ecologicamente adaptada.

Observou-se diferença significativa para

Tabela II. Teores médios de matéria seca (MS), proteina bruta (PB) e matéria mineral (MM) de plantas de sabiá, conforme a fração da planta e período do ano. (Average contents of dry matter (MS), crude protein (PB) and mineral matter (MM) of sabiá plants, according to plant fraction and season of the year).

\begin{tabular}{lcccccr}
\hline \multirow{2}{*}{ Período do ano } & \multicolumn{2}{c}{ MS (\%) } & \multicolumn{2}{c}{ PB (\%) } & \multicolumn{2}{c}{ MM (\%) } \\
& Folha & Ramo & Folha & Ramo & Folha & Ramo \\
\hline Chuva & $30,21^{\mathrm{a}}$ & $43,55^{\mathrm{b}}$ & $22,12^{\mathrm{a}}$ & $7,98^{\mathrm{a}}$ & $6,58^{\mathrm{a}}$ & $3,53^{\mathrm{a}}$ \\
Seca & $43,04^{\mathrm{a}}$ & $49,78^{\mathrm{a}}$ & $16,69^{\mathrm{b}}$ & $5,66^{\mathrm{b}}$ & $6,02^{\mathrm{b}}$ & $3,40^{\mathrm{a}}$ \\
CV (\%) & 20 & 21 & 24 & 26 & 8 & 20 \\
& & 21 & & &
\end{tabular}

${ }^{a b}$ Médias seguidas de mesma letra na coluna, não diferem entre si pelo teste $F(p>0,05)$.

Archivos de zootecnia vol. 59, núm. 228, p. 534. 
fibra em detergente neutro (FDN) das folhas conforme a época do ano (tabela III), ocorrendo valores superiores para época seca. Independente da fração da planta, maiores valores foram observados no período seco para fibra em detergente ácido (FDA). Os valores encontrados para FDN e FDA foram superiores aos relatados por Vieira et al. (2005) que encontram valores de 44,39 e 39,05\% de FDN para época chuvosa e seca, respectivamente e 25,80 e $21,83 \%$ de FDA para época chuvosa e seca, respectivamente. Tais diferenças, provavelmente estão associadas à determinação ter sido efetuada na planta inteira no referido trabalho, bem como aos efeitos dos fatores idade da planta, precipitação, complexo tanino:proteína na proporção de parede celular.

Considerando-se que houve interação $(\mathrm{p}<0,05)$ entre período de avaliação e adubação fosfatada para a FDN dos ramos, observaram-se maiores valores para FDN na estação seca (tabela IV), talvez devido ao maior crescimento das plantas, já que o corte de uniformização ocorreu no meio do período chuvoso, com aumento do crescimento (tabela I) e possível aceleração do processo de deposição de fibra.

Os resultados referentes aos teores

Tabela III. Teores médios de fibra em detergente neutro (FDN) e fibra em detergente ácido (FDA) de plantas de sabiá, conforme o período do ano e fração da planta. (Average content of neutral detergent fiber (FDN) and acid detergent fiber (FDA) of sabiá plants, according to season of the year and plant fraction).

\begin{tabular}{lccc}
\hline & \multirow{2}{*}{ FDN (\%) } & \multicolumn{2}{c}{ FDA (\%) } \\
Período do ano & Folha & Folha & Ramo \\
\hline Chuva & $42,66^{\mathrm{b}}$ & $29,69^{\mathrm{b}}$ & $51,58^{\mathrm{b}}$ \\
Seca & $53,05^{\mathrm{a}}$ & $37,10^{\mathrm{a}}$ & $54,97^{\mathrm{a}}$ \\
CV (\%) & 4 & 22 & 9 \\
\hline
\end{tabular}

${ }^{a b}$ Médias seguida de mesma letra na coluna, não diferem entre si pelo teste $F(p>0,05)$.
Tabela IV. Teores médios de fibra em detergente neutro $(F D N, \%)$ de ramos de plantas de sabiá, conforme período do ano e adubaçãofosfatada. (Average neutral detergent fiber of sabiá plant branches, according to season of the year and phosphorus fertilization).

\begin{tabular}{|c|c|c|}
\hline \multirow{2}{*}{$\begin{array}{l}\text { Tratamento } \\
\mathrm{kg} \text { de } \mathrm{P}_{2} \mathrm{O}_{5} / \mathrm{ha}\end{array}$} & \multicolumn{2}{|c|}{ Período do ano } \\
\hline & chuva & seca \\
\hline 0 & $64,83^{\mathrm{Ba}}$ & $72,54^{\mathrm{Aa}}$ \\
\hline 100 & $64,88^{\mathrm{Ba}}$ & $73,91^{\text {Aa }}$ \\
\hline 200 & $59,80^{\text {ва }}$ & $75,64^{\text {Aa }}$ \\
\hline CV adubação (\%) & & \\
\hline CV época (\%) & & \\
\hline
\end{tabular}

Valores em uma mesma coluna seguidos por letras minúsculas idênticas não diferem pelo teste de Tukey $(p>0,05)$, e maiúsculas em uma mesma linha, não diferem entre si pelo teste $F(p>0,05)$.

médios de PB, FDN e FDA no presente trabalho, concordam com os relatos feitos por Araújo Filho et al. (2002) e GuimarãesBeelen et al. (2006), que observaram que com o avanço da estação seca ocorre diminuição no teor de PB e aumento da fração fibrosa da planta.

Observou-se efeito significativo $(\mathrm{p}<0,05)$ para época apenas para folha no que se refere à matéria mineral, sendo encontrados valores superiores para o período chuvoso (tabela II). Para o teor médio de fósforo, observou-se diferença com relação à época, sendo o maior teor observado nas folhas e no período chuvoso (tabela V). Os resultados obtidos foram de $0,19 \%$ e $0,10 \%$ para folhas e ramos, sendo próximos aos relatados por Vieira et al. (2005) que encontraram valores de $0,15 \%$ e $0,22 \%$ no período seco e chuvoso, respectivamente.

Segundo Haag et al. (1985), a concentração de alguns elementos químicos nas folhas eleva-se enquanto a de outros decresce e ocorre uma translocação de nutrientes de órgãos senescentes para as regiões de crescimento da árvore. Moura et 
al.(2006) também observaram que as folhas de plantas de sabiá apresentaram as maiores concentrações em todos os nutrientes em relação aos outros componentes da planta, sendo as folhas um grande reservatório de nutrientes e importante na manutenção da fertilidade do solo e como forrageira.

Quanto ao tanino, observou-se maior valor para a época seca, tanto para folha como para ramos (tabela V e VI). No entanto, houve efeitos independentes do período de avaliação e da adubação fosfatada $(\mathrm{p}<0,05)$ para o teor de tanino dos ramos (tabela VI). A adubação com $200 \mathrm{~kg}$ de $\mathrm{P}_{2} \mathrm{O}_{5} /$ ha resultou em menor teor de tanino, não havendo diferença significativa entre os níveis de 0 e 100 de $\mathrm{P}_{2} \mathrm{O}_{5}$. Os valores de tanino encontrados foram inferiores a $2 \%$, o que pode ser considerado baixo de acordo com Poncet e Rémond (2002), que afirmaram que a digestibilidade da proteína não é afetada por concentrações de tanino abaixo de $2 \%$. Além do teor de tanino total, vale sua constituição. Neste sentido, GuimarãesBeelen et al. (2006) observaram que os taninos condensados presentes em sabiá são principalmente constituídos de prodelfinidina, sendo a relação prodelfinidina: procianidina de 90:20 nas fases de vegetação plena e floração, diminuindo para 40:50 na fase de frutificação.

Almeida et al. (2006b) não encontraram

Tabela $V$. Teores médios de fósforo e tanino de plantas de sabiá, conforme a fração da planta e período do ano. (Average phosphorus and tannin content of sabiá plants, according to plant fraction and season of the year).

\begin{tabular}{|c|c|c|c|}
\hline \multirow[t]{2}{*}{ Período do ano } & \multicolumn{2}{|c|}{ Fósforo (\%) } & \multirow{2}{*}{$\begin{array}{c}\text { Tanino }(\%) \\
\text { Folha }\end{array}$} \\
\hline & Folha & Ramo & \\
\hline Chuva & $0,21^{a}$ & $0,09^{b}$ & $0,81^{\mathrm{b}}$ \\
\hline Seca & $0,17^{b}$ & $0,11^{\mathrm{a}}$ & $1,93^{a}$ \\
\hline CV & 26 & 20 & 18 \\
\hline
\end{tabular}

Médias seguidas de igual letra, não diferem entre si pelo teste $F(p>0,05)$.
Tabela VI. Teores médios de tanino de ramos plantas de sabiá, conforme o período do ano e adubação fosfatada. (Average tanning conten of sabiá plant branches, according to season of the year and phosphorus fertilization).

\begin{tabular}{lcc}
\hline $\begin{array}{l}\text { Período do ano/ } \\
\text { kg de } \mathrm{P}_{2} \mathrm{O}_{5} / \text { ha }\end{array}$ & Tanino (\%) & CV (\%) \\
\hline Chuva & $0,67^{\mathrm{B}}$ & 31 \\
Seca & $1,08^{\mathrm{A}}$ & \\
$\mathrm{kg} \mathrm{de} \mathrm{P}_{2} \mathrm{O}_{5} / \mathrm{ha}$ & & \\
0 & $0,96^{\mathrm{a}}$ & \\
100 & $0,94^{\mathrm{a}}$ & 55 \\
200 & $0,73^{\mathrm{b}}$ &
\end{tabular}

Médias seguidas de igual letra maiúscula, não diferem entre si pelo teste $F(p>0,05)$.

Médias seguidas por igual letra minúscula, não diferem entre si pelo teste Tukey $(p>0,05)$.

diferenças entre épocas para teor de tanino e Araújo Filho et al. (2002) encontraram variação do teor de tanino nas diferentes fases fenológicas da planta, sendo os valores de tanino observados por esse autores mais altos do que os observados no presente trabalho.

De maneira geral a adubação fosfatada promoveu pequenos efeitos nas características morfológicas e na composição química da planta de sabiá, provavelmente devido ao sistema radicular bastante desenvolvido das plantas. Por outro lado, os níveis estudados podem ser considerados baixos ou médios, não tendo sido aplicados níveis elevados de $\mathrm{P}_{2} \mathrm{O}_{5}$ ao ponto de modificar de forma acentuada a composição do solo e da planta, bem como de seus componentes morfológicos. Vale ressaltar também, que o P é pouco móvel no solo e sob as condições de Itambé, com o pH ácido, este nutriente provavelmente ficou menos disponível.

\section{CONCLUSÕES}

A adubação fosfatada promove efeito

Archivos de zootecnia vol. 59, núm. 228, p. 536. 


\section{ADUBAÇÃO DE MIMOSA CAESALPINIIFOLIA COM P}

de pequena magnitude nos componentes morfológicas e na composição química de plantas de sabiá.

$\mathrm{Na}$ época chuvosa observa-se melhor composição química da planta, notadamente da fração folha.

\section{BIBLIOGRAFIA}

Almeida, A.C.S., Ferreira, R.L.C., Dos Santos, M.V.F., Silva, J.A.A. e Lira, M. de A. 2006a. Caracterização de produtores e propriedades rurais em três municípios do estado de Pernambuco. Caatinga, 19: 323-332.

Almeida, A.C.S., Ferreira, R.L.C., Dos Santos, M.V.F., Silva, J.A.A., Lira, M. de A. e Guim, A 2006b. Avaliação bromatológica de espécies arbóreas e arbustivas de pastagens em três municípios do estado de Pernambuco. Acta Sci. Anim. Sci., 28: 1-9.

AOAC. 1995. Association of Official Analytical Chemists. Official methods of analysis. $16^{\text {th }}$ edition. AOAC. Washington. 1018 pp.

Araújo Filho, J.A. de A., Carvalho, F.C. y Silva, N.L. 2002. Fenología y valor nutritivo de follajes de algunas especies forrajeras de la Caatinga. Agroforesteria en las Americas, 9: 33-34.

Burity, H.A., Lyra, M.C.C.P., Souza, E.S. de, Mergulhão, A.C. do E.S. e Silva, M.L.R.B. 2000. Efetividade da inoculação com rizóbio e fungos micorrízicos arbusculares em mudas de sabiá submetidas a diferentes níveis de fósforo. Pesqui. Agropecu. Bras., 35: 801-807.

Carvalho, G.G.P. ePires, A.J.V. 2008. Organização dos tecidos de plantas forrageiras e suas implicações para os ruminantes. Arch. Zootec., 57R: 13-28.

CPRH. 2003. Companhia Pernambucana do Meio Ambiente. Diagnóstico sócio ambiental do Litoral Norte de Pernambuco. CPRH. Recife.

Drumond, M.A., Santana, A.C. e Antoniole, A. 2004. Recomendações para o uso sustentável da biodiversidade no bioma da caatinga. Em: Biodiversidade da Caatinga: Áreas e ações prioritárias para a conservação. Ministério do Meio Ambiente. Brasília. pp. 47-90.

EMBRAPA. 1997. Manual de métodos de análise de solos. $2^{\text {a }}$ ed. EMBRAPA-CNPS. Rio de Janeiro. EMBRAPA. 1999. Empresa Brasileira de Pesquisa

\section{AGRADECIMENTOS}

Ao CNPq pelas bolsas de produtividade em pesquisa concedidas ao segundo, terceiro, quarto e sexto autores. A CAPES pelo financiamento parcial da pesquisa.

Agropecuária. Sistema brasileiro de classificação de solos. EMBRAPA-Produção de Informação. Brasília.

Guimarães-Beelen, P.M., Berchielli, T. T., Beelen, R., Araújo Filho, J. and Oliveira, S.G. 2006. Characterization of condensed tannins from native legumes of the Brazilian Southeastern Semi-Arid. Sci. Agric., 63: 522-528.

Haag, H.P., Valera, F.P. e Chiaranda, R. 1985. Ciclagem de nutrientes em florestas tropicais. Fundação Cargil. Campinas.

IPA. 1994. Empresa Pernambucana de Pesquisa Agropecuária. Banco de dados agrometeorológicos. IPA. Recife.

Lima, I.C.A.R., Lira, M. de A., Mello, A. C. L., Dos Santos, M.V.F., Freitas, E.V. e Ferreira, R.L.C. 2008. Avaliação de sabiazeiro (Mimosa caesalpiniifolia Benth.) quanto a acúleos e preferência por bovinos. Rev. Bras. Ciênc. Agrár., 3: 289-294.

Lira, M.A., Lima, I.C.A.R., Freitas, E.V. e Farias, I. 1996. Estudo do sabiazeiro para forragem. Em: Simpósio Nordestino de Alimentação de Ruminantes Natal, 1996. Anais... Natal. UFRN. Brasil. pp. 175-176.

Moreira, A., Malavolta, E. e Moraes, L.A.C. 2002. Eficiência de fontes e doses de fósforo na alfafa e centrosema cultivadas em Latossolo Amarelo. Pesqui. Agropecu. Bras., 37: 14591466.

Moura, O.N., Passos, M.A.A., Ferreira, R.L.C., Molica, S.G., Lira Júnior, M. de A., Lira, M.A. e Dos Santos, M.V.F. 2006. Distribuição de biomassa e nutrientes na parte aérea de Mimosa caesalpiniifolia Benth. Rev. Árvore, 30: 877884

Oliveira, F.H.T., Novais, R.F. e Alvarez, V.V.H. 2002. Fertilidade do solo no plantio direto. Em: Alvarez, V.V.H., C.E.G.R. Schaefer, N.F. Barros (Eds.). Tópicos em Ciência do Solo. 


\section{CALDAS ET AL.}

Sociedade Brasileira de Ciência do Solo. Viçosa Vol. II. pp. 393-486.

Pereira Filho, J.M.P., Vieira, E.L., Kamalak, A., Silva, A.M.A., Cezar, M.F. and Beelen, P.M.G 2007. Ruminal disappearance of Mimosa tenuiflora hay treated with sodium hydroxide. Arch. Zootec., 56: 959-962.

Pimentel-Gomes, F.P. 2000. Curso de Estatística Experimental. $14^{\circ}$ ed. ESALQ/USP. São Paulo.

Poncet, C. and Rémond, D. 2002. Rumen digestion and intestinal nutrient flows in shepp consuming pea seeds: the effect of extrusion or chestnut tannin addition. Anim. Res., 51: 201-216.

Sas Institute. 1999. SAS/STAT User's guide. Version 8. SAS. Cary.

Silva, D.J. e Queiroz, A.C. 2002. Análise de alimen- tos: métodos químicos e biológicos. $3^{\mathrm{a}}$ ed. Universidade Federal de Viçosa. Viçosa.

Van Soest, P.J. 1967. Development of a comprehensive sistem of feed analysis and its application to foragens. J. Anim. Sci., 26: 119128.

Van Soest, P.J. 1994. Nutritional ecology of ruminant. Cornell University Press. Ithaca.

Vieira, E.L., Carvalho, F.F.R., Batista, Â.M.V., Ferreira, R.L.C., Dos Santos, M.V.F., Lira, M. de A., Silva, M.J. e Bonfim-Silva, E.M. 2005 Composição química de forrageiras e seletividade de bovinos em bosque-de-Sabiá (Mimosa caesalpiniifolia Benth.) nos períodos chuvoso e seco. Rev. Bras. Zootecn., 34: 15051511.

Archivos de zootecnia vol. 59, núm. 228, p. 538. 